\title{
Animal Studies on Venom Neutralization potential of Metal-Herbal (Copper-Leucas zeylanica) Nanocomposites (MHNC) Against Naja naja and Bungarus Caeruleus Venoms
}

\author{
Pooja S Dev ${ }^{1}$, Dr. S. Meenatchisundaram ${ }^{2 *}$ \\ ${ }^{1}$ Research scholar, Nehru arts and science college, Coimbatore, TamilNadu, India, Email: \\ sastri.devpooja@gmail.com \\ ${ }^{2}$ Associate Professor, Department of Microbiology, Shri Nehru Maha Vidyalaya College of Arts
$\&$ Science, Coimbatore, Tamil Nadu, India, Email: drmscbe@ gmail.com (Corresponding author)
}

Corresponding author:

Dr. S. Meenatchisundaram

email: drmscbe@gmail.com 


\begin{abstract}
Objectives: The present study focuses on development of novel Metal-Herbal Nano composite (MHNC) formulation against Naja naja and Bungarus Caeruleus venoms on animal models.
\end{abstract}

Methods: The venoms were procured from Irula snake catchers society in lyophilised forms. Herbal-metal nanocomposites were prepared in 1:1 combinations. Single strength concentration of Leucas zeylanica extracts and copper oxide metal nanoparticles was used to attain these ratio's. In vivo venom neutralization analysis was carried out in Swiss albino mice. The $\mathrm{LD}_{50}$ and $\mathrm{ED}_{50}$ of the MHNC were determined.

Results: The $\mathrm{LD}_{50}$ of the Naja naja venom was observed to be $0.19 \mu \mathrm{g} / \mathrm{g}$ and $0.174 \mu \mathrm{g} / \mathrm{g}$ for Bungarus Caeruleus venom. The $\mathrm{ED}_{50}$ of the MHNC against Naja naja venom was observed to be $14.22 \mathrm{mg}$ and $63.39 \mathrm{mg}$ for Bungarus Caeruleus venom.

Conclusion: The MHNC developed in this study has significant venom neutralization potential against Naja naja and Bungarus Caeruleus venoms. Therefore, the MHNC can be used for development of anti-venom drugs.

Keywords: Naja naja, Bungarus Caeruleus, Metal-Herbal conjugates, venom neutralization, animal studies 


\section{Introduction}

Snake venom is a complex cocktail of majorly proteins (enzymatic, non-enzymatic proteins) and other components like inorganic ions, carbohydrates, lipids, amines and nucleotides found in minor quantities. Synergistic effect of enzymatic and non-enzymatic components is responsible for clinical effects of venom (Goswami et al., 2014). Snake envenomation is a neglected tropical disease listed under Category A by the World Health Organization. In India, 49,500 mortality occurs due to snake bite. 'BIG FOUR' snakes of India namely, Bungarus caeruleus (krait), Naja (cobra), Echis carinatus (saw-scaled viper) and Daboia russelii (Russell's viper) are medically important snakes, as they are responsible for highest mortality and morbidity (Sinha, 2011).

The Indian cobra (Naja naja), also known as the spectacled cobra, Asian cobra, or binocellate cobra, is a species of the genus Naja found, in India, Pakistan, Bangladesh, Sri Lanka, Nepal, and Bhutan, and a member of the "big four" species that inflict the most snakebites on humans in India. It is distinct from the king cobra which belongs to the monotypic genus Ophiophagus. Indian cobras ( $N$. naja) earliest clinical manifestation of systemic envenoming was drowsiness, which occurred in $60 \%$ of cases starting starting at 30 minutes (severe bites) post-envenomation to 3 hours post bite (Sivaraman et al., 2017). Difficulty in opening the eyes, speaking, opening the mouth, moving the lips and swallowing followed 1 - 4 hours later. Ptosis developed 1.6 - 6 hours post bite in all cases of systemic envenoming. General weakness was usually the last symptom to develop, followed by paralysis of the muscles in severe cases. Three patients developed respiratory paralysis and were given artificial respiration; 2 recovered and 1 died. The fatal case developed respiratory paralysis about 10 minutes before reaching hospital and patient became comatose; tracheostomy and artificial respiration were performed immediately and antivenom was administered intravenously. Patient survived for 8 days but finally died. The outstanding feature of systemic envenoming is paralysis of the muscles due to rapid action of neurotoxin at the myoneural junction. Respiratory paralysis may occur within 3 - 4 hours in severe cases (Chen et al., 2020).

The common krait (Bungarus caeruleus), also known as the blue krait, is a species of highly venomous snake of the genus Bungarus native to the Indian subcontinent. It is a member of the "big four" species, inflicting the most snakebites on humans in Bangladesh and India. When agitated, it will coil up with its head concealed and body flattened, and makes jerky movements. It may also lift its tail. It is reluctant to bite, but when 
it does, it typically holds on for a while, which enables it to inject considerable amounts of venom. It may become aggressive at night if threatened since this is its active time. It is responsible for the second highest number of snake bites in India for a single species. In Bangladesh its responsible for $28 \%$ of total Krait bites (Theakston et al., 1990).

Polyvalent anti-snake venom (PASV), sera obtained from immunized horse against BIG FOUR is the currently available treatment for snake bite in India. However, factors like storage, side-effects induced, neutralization of only free circulating venom components, and decreasing efficiency of PASV over years has led to search for new alternate therapies to treat snake-bite (Amin et al., 2008). Therefore, the present research focuses on development of novel copper- of Metal-Herbal (Copper-Leucas zeylanica) Nanocomposite (MHNC) against Naja naja and Bungarus caeruleus Venoms in animal models. The LD50 of the venoms were determined and ED50 of the MHNC also determined.

\section{Methodology}

\section{Procurement of snake venom}

The lyophilized form of Naja naja and Bungarus Caeruleus venoms were obtained from Irula's Snake Catchers Industrial Co-operative Society Limited Chennai and were stored at $4^{\circ} \mathrm{C}$. Stock solution was prepared by dissolving $1 \mathrm{mg}$ of lyophilized venom in $1 \mathrm{ml}$ of physiological saline $(1 \mathrm{mg} / \mathrm{ml})$.

\section{Medicinal Plants and Preparation of Extract (Uhegbu et al., 2005)}

Fresh plants of Leucas zeylanica were collected at Kottayam, Kerala.. The plants were authenticated by Dr. M. U. Sharief and the authentication number is BSI/SRC/5/23/2021/Tech./32. The leaves were finely grounded and stored in sterile containers (Figure-1). About $20 \mathrm{~g}$ of powdered sample of the herb was extracted by soaking in $180 \mathrm{ml}$ of distilled water in a beaker, stirred for about $6 \mathrm{~min}$ and left over night. Thereafter, the solution was filtered using filter paper (What man No. 1) and the extracts were evaporated to dryness under reduced pressure on $40^{\circ} \mathrm{C}$. The plant extracts were expressed in terms of dry weight. 


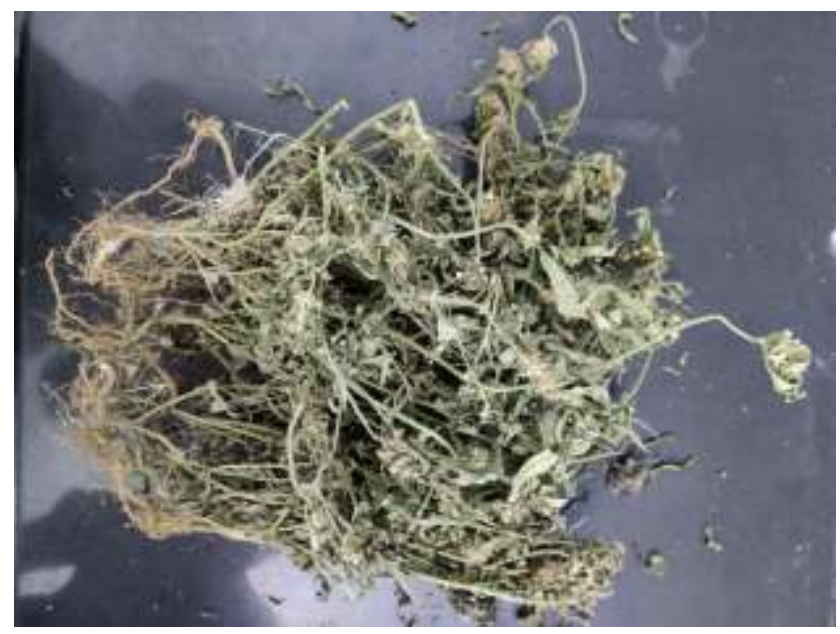

Figure-1: Dried plants of Leucas zeylanica

\section{Purification of extracts by Column Chromatography}

The extracts were purified by column chromatography technique. A long cylindrical glass column (450mm X 20mm) should be stand firm on a column chromatography stand was selected for the present research. Silica gel (60 - 120 mesh) was packed with the aid of hexane without any air bubbles. The Leucas zeylanica extracts were distilled dried and finely powdered form for easy distribution of sample in already packed silica gel column. Sample powdered mass was placed on the top of the pre-packed silica column and sample was covered with a layer of cotton. Then solvents (100\% hexane) were passed through column at uniform rate under gravity to fractionate the sample extract. Each fraction was collected separately in a test tube and numbered consecutively for further analysis and about 7 different fractions were collected.

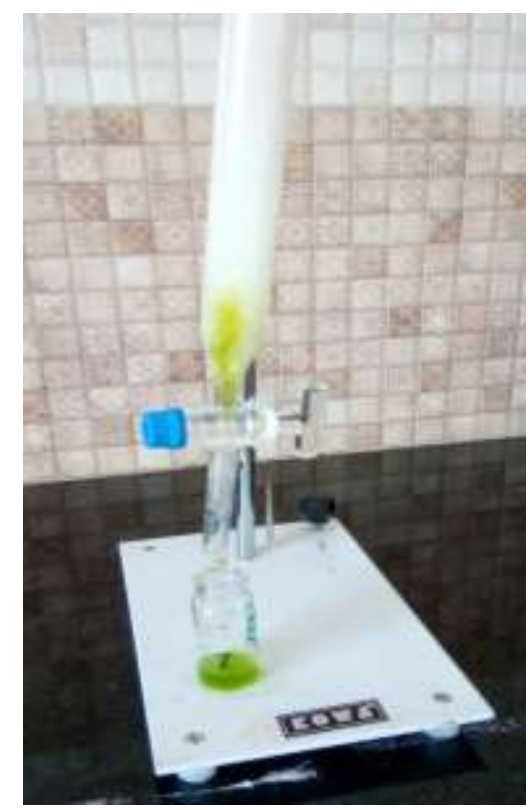

Figure-2: Purification of phytochemical compounds by column chromatography 


\section{Metal-Herbal nanocomposite preparation (Ghulam et al., 2013)}

Herbal and metal nanocomposites were prepared in 1:1 combinations. Single strength concentration of herbal and copper oxide metal nanoparticles was used to attain these ratio's. For 1:1 herbal metal nano composites, $100 \mathrm{mg}$ of Leucas zeylanica extracts were dispersed in $1 \mathrm{~mL}$ of sterile distilled water was added drop wise to $100 \mathrm{mg}$ nano metal solution. Herbal solution was added at the rate of $1 \mathrm{~mL} \mathrm{~min}^{-1}$. The composites were continuously stirred and the developed MHNC were used for the further analysis.

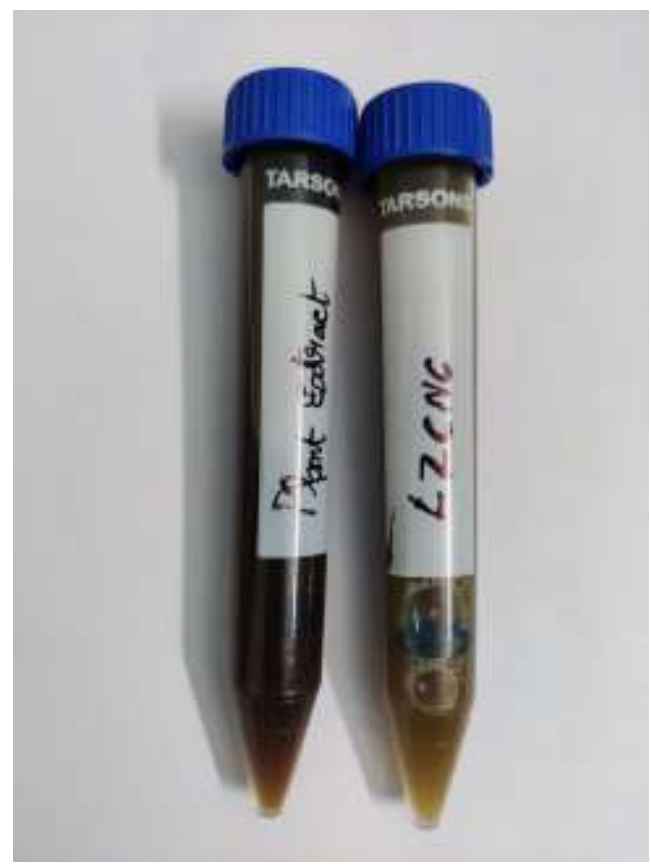

Figure-3: Leucas zeylanica extracts and MHNC prepared in the study

\section{Animals}

Male Swiss albino mice weighing between $20-25$ gm were used in the study. The animals were obtained from animal house, Kerala Veterinary and Animal Science, Mannuthy, Kerala. On arrival, the animals were placed at animal house, Nandha College of Pharmacy, Erode and randomly allocated to treatment groups in polypropylene cages with paddy husk as bedding.Animals were housed at a temperature of $24 \pm 2^{\circ} \mathrm{C}$, relative humidity of $30-70 \%$ and a 12:12 light:day cycle was followed. All animals were allowed to free access to water and fed with standard commercial pelleted rat chaw (M/s. Hindustan Lever Ltd, Mumbai). All the experimental procedures and protocols used in this study were reviewed and approved by tthe Institutional Animal Ethics Committee of Nandha College of Pharmacy (Reg No: 688 / PO/Re/S/02 / CPCSEA) and were in accordance with the guidelines of the CPCSEA (Proposal Number: NCP/IAEC/2020-21/40). 


\section{In vivo Assessment of Venom Toxicity}

The median lethal dose $\left(\mathrm{LD}_{50}\right)$ of various (Cobra, RV, SSV and Krait) venoms were determined according to the method of Randhawa (1944). Various doses of venoms in $0.2 \mathrm{~mL}$ of physiological saline were injected into the tail vein of mice, using groups of 3-5 mice for each venom dose. The $\mathrm{LD}_{50}$ was calculated with confidence limit at $50 \%$ probability by the analysis of deaths occurring within $24 \mathrm{~h}$ of venom injection. The anti-lethal potentials for plant extract were determined against $\mathrm{LD}_{50}$ of various venoms.

\section{Anti-venom Effect of Leucas zeylanica Nano Composite}

Various amount of Nano-Composite of Leucas zeylanica $(\mu \mathrm{L})$ were mixed with $\mathrm{LD}_{50}$ of venom sample and incubated at $37{ }^{\circ} \mathrm{C}$ for 30 minutes and then injected intravenously into mice. 3-5 mice were used at each antivenom dose. The median Effective Dose $\left(\mathrm{ED}_{50}\right)$ was calculated from the number of deaths within $24 \mathrm{~h}$ of injection of the venom/antivenom mixture. $\mathrm{ED}_{50}$ was expressed as $\mu \mathrm{L}$ antivenom/mouse and calculated by probit analysis. 


\section{Results and Discussion}

\section{Lethal dosage (LD50) determination of Naja naja and Bungarus Caeruleus venoms}

Lethality dosage $\left(\mathrm{LD}_{50}\right)$ of snake venoms was evaluated by administering different concentrations of the venoms. The death percentage of the mice was observed for each concentration and $\mathrm{LD}_{50}$ values were determined using the formula. From the analysis the $\mathrm{LD}_{50}$ of the Naja naja venom was observed to be $0.19 \mu \mathrm{g} / \mathrm{g}$ and $0.174 \mu \mathrm{g} / \mathrm{g}$ for Bungarus Caeruleus venom. Table- 1 and 2 shows the death ratio of snake venoms on mice based on its concentrations. Figure- $4 \& 5$ shows the graphical representation of the LD values.

Table-1: Calculation of $\mathrm{LD}_{50}$ of Naja naja venom

\begin{tabular}{|c|c|c|c|c|c|c|}
\hline Dose ( $\begin{array}{c}\text { Adjusted } \\
\text { Dose } \\
(\text { Dose } \\
\mathbf{1 0 0})\end{array}$ & Log Dose & Death/Total & Dead\% & $\begin{array}{c}\text { Corrected } \\
\text { Formula \% }\end{array}$ & $\begin{array}{c}\text { Probit } \\
\text { Score }\end{array}$ \\
\hline 0.05 & 5 & 0.6989 & $0 / 5$ & 0 & 5 & 3.36 \\
\hline 0.1 & 10 & 1.000 & $1 / 5$ & 20 & 20 & 4.16 \\
\hline 0.15 & 15 & 1.1761 & $2 / 5$ & 40 & 40 & 4.75 \\
\hline 0.2 & 20 & 1.3010 & $2 / 5$ & 40 & 40 & 4.75 \\
\hline 0.25 & 25 & 1.3979 & $3 / 5$ & 60 & 60 & 5.25 \\
\hline 0.3 & 30 & 1.4771 & $3 / 5$ & 60 & 60 & 5.25 \\
\hline 0.35 & 35 & 1.5441 & $4 / 5$ & 80 & 80 & 5.84 \\
\hline 0.4 & 40 & 1.6021 & $5 / 5$ & 100 & 95 & 6.64 \\
\hline
\end{tabular}


Table-2: Calculation of $\mathbf{L D}_{50}$ of Krait venom in mice

\begin{tabular}{|c|c|c|c|c|c|c|}
\hline Dose $(\boldsymbol{\mu g})$ & $\begin{array}{c}\text { Adjusted } \\
\text { Dose } \\
(\text { Dose } \\
\mathbf{1 0 0})\end{array}$ & Log Dose & Death/Total & Dead\% & $\begin{array}{c}\text { Corrected } \\
\text { Formula \% }\end{array}$ & $\begin{array}{c}\text { Probit } \\
\text { Score }\end{array}$ \\
\hline 0.05 & 5 & 0.6989 & $0 / 5$ & 0 & 5 & 3.36 \\
\hline 0.1 & 10 & 1.000 & $1 / 5$ & 20 & 20 & 4.16 \\
\hline 0.15 & 15 & 1.1761 & $2 / 5$ & 40 & 40 & 4.75 \\
\hline 0.2 & 20 & 1.3010 & $2 / 5$ & 40 & 40 & 4.75 \\
\hline 0.25 & 25 & 1.3979 & $3 / 5$ & 60 & 60 & 5.25 \\
\hline 0.3 & 30 & 1.4771 & $4 / 5$ & 80 & 80 & 5.84 \\
\hline 0.35 & 35 & 1.5441 & $5 / 5$ & 100 & 95 & 6.64 \\
\hline 0.4 & 40 & 1.6021 & $5 / 5$ & 100 & 95 & 6.64 \\
\hline
\end{tabular}

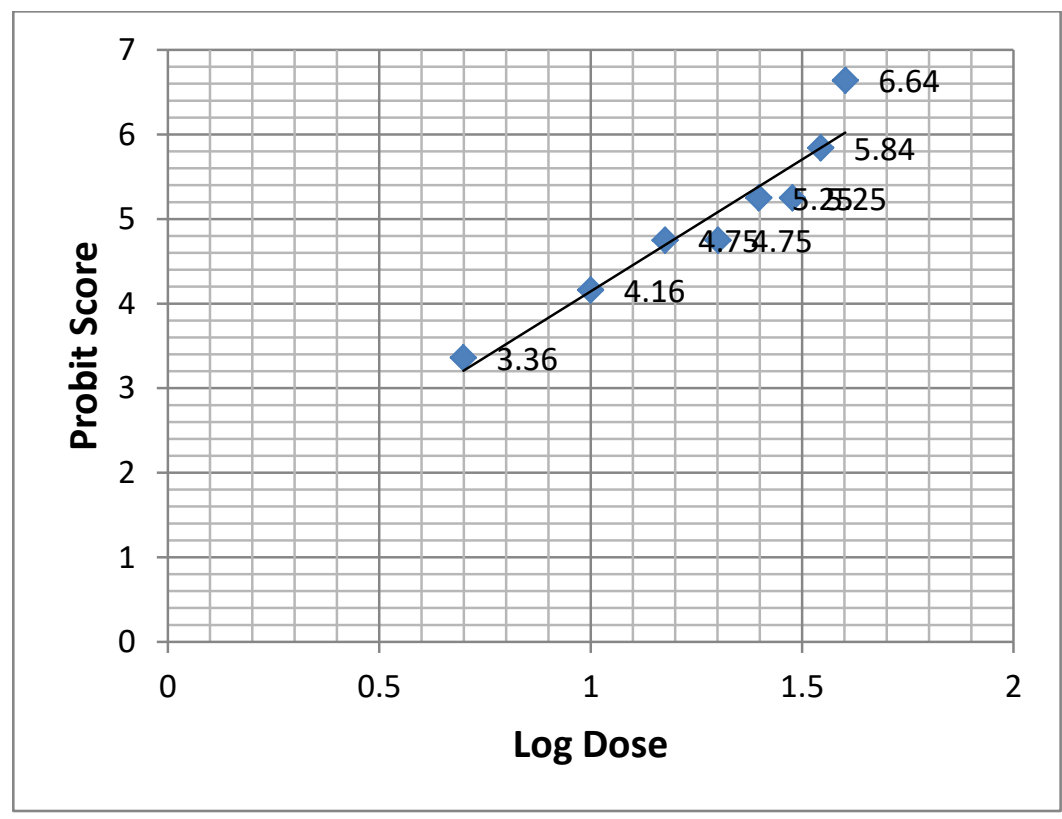

Figure-4: Graphical representation of the $\mathrm{LD}_{50}$ analysis of Naja naja venom 


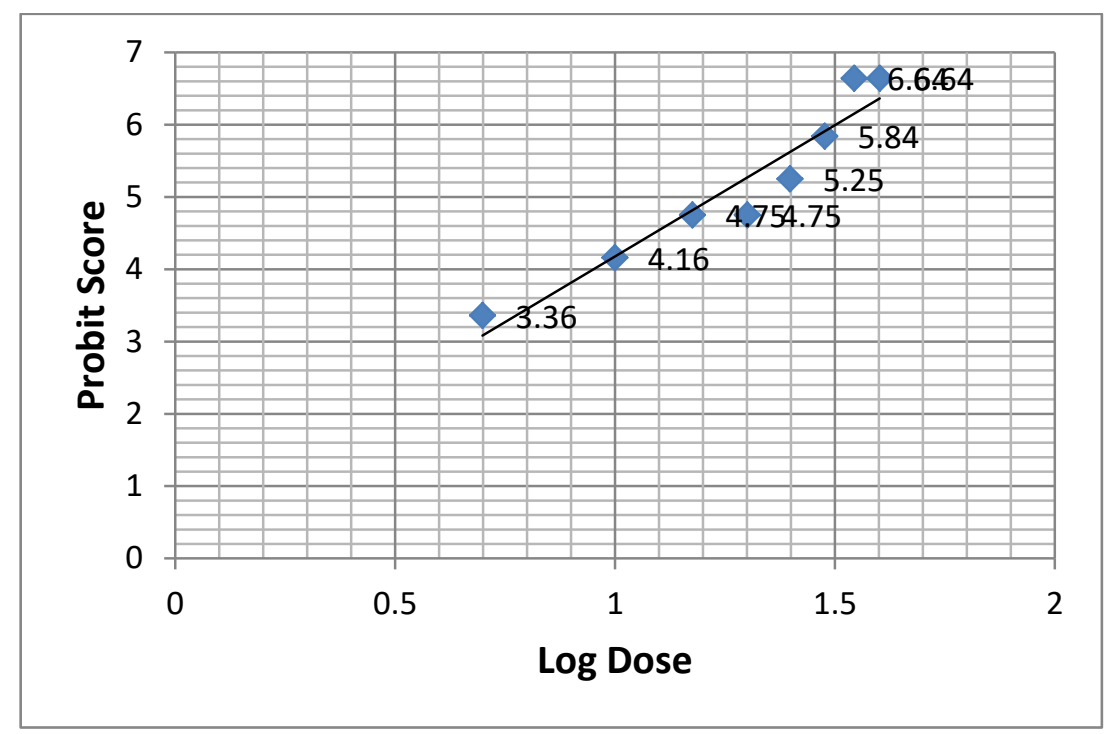

Figure-5: Graphical representation of the $\mathrm{LD}_{50}$ analysis of Bungarus Caeruleus venom

Effective dosage (ED (50) $_{\text {of }}$ MHNC against Naja naja and Bungarus Caeruleus venoms

The effective dose of MHNC was determined by treating the LD50 of venom with different concentrations of MHNC. $100 \%$ mice survival was observed at treatment of MHNC at $128 \mu \mathrm{g} / \mathrm{g}$. From the analysis the $\mathrm{ED}_{50}$ of the $\mathrm{MHNC}$ against Naja naja venom was observed to be $14.22 \mathrm{mg}$ and $63.39 \mathrm{mg}$ for Bungarus Caeruleus venom. Table- 3 and 4 shows the survival ratio of snake venoms on mice based on MHNC concentrations. Figure-6 \& 7 shows the graphical representation of the ED values.

Table-3: Calculation of $\mathrm{ED}_{50}$ of Leucas zeylanica Nano-Comosite against Cobra venom in mice

\begin{tabular}{|c|c|c|c|c|c|c|}
\hline $\begin{array}{c}\text { Dose } \\
(\boldsymbol{\mu g} / \mathbf{g})\end{array}$ & $\begin{array}{c}\text { Adjusted } \\
\text { Dose } \\
(\text { Dose } \mathbf{x} \\
\mathbf{1 0 0})\end{array}$ & Log Dose & Survival/Total & Dead\% & $\begin{array}{c}\text { Corrected } \\
\text { Formula \% }\end{array}$ & $\begin{array}{c}\text { Probit } \\
\text { Score }\end{array}$ \\
\hline 0.5 & 50 & 1.6989 & $0 / 5$ & 0 & 5 & 3.36 \\
\hline 1 & 100 & 2.0000 & $0 / 5$ & 0 & 5 & 3.36 \\
\hline 2 & 200 & 2.3010 & $1 / 5$ & 20 & 20 & 4.16 \\
\hline 4 & 400 & 2.6021 & $1 / 5$ & 20 & 20 & 4.16 \\
\hline 8 & 800 & 2.9031 & $1 / 5$ & 20 & 20 & 4.16 \\
\hline 16 & 1600 & 3.2041 & $2 / 5$ & 40 & 40 & 4.75 \\
\hline 32 & 3200 & 3.5051 & $3 / 5$ & 60 & 60 & 5.25 \\
\hline 64 & 6400 & 3.8062 & $4 / 5$ & 80 & 80 & 5.84 \\
\hline 128 & 12800 & 4.1072 & $5 / 5$ & 100 & 95 & 6.64 \\
\hline
\end{tabular}


Table-4: Calculation of $\mathrm{ED}_{50}$ of Leucas zeylanica Nano-Comosite against Krait venom in mice

\begin{tabular}{|c|c|c|c|c|c|c|}
\hline $\begin{array}{c}\text { Dose } \\
(\boldsymbol{\mu g} / \mathbf{g})\end{array}$ & $\begin{array}{c}\text { Adjusted } \\
\text { Dose } \\
(\text { Dose } \mathbf{x} \\
\mathbf{1 0 0})\end{array}$ & Log Dose & Survival/Total & Dead \% & $\begin{array}{c}\text { Corrected } \\
\text { Formula \% }\end{array}$ & $\begin{array}{c}\text { Probit } \\
\text { Score }\end{array}$ \\
\hline 0.5 & 50 & 1.6989 & $0 / 5$ & 0 & 5 & 3.36 \\
\hline 1 & 100 & 2.0000 & $1 / 5$ & 20 & 20 & 4.16 \\
\hline 2 & 200 & 2.3010 & $2 / 5$ & 40 & 40 & 4.75 \\
\hline 4 & 400 & 2.6021 & $2 / 5$ & 40 & 40 & 4.75 \\
\hline 8 & 800 & 2.9031 & $3 / 5$ & 60 & 60 & 5.25 \\
\hline 16 & 1600 & 3.2041 & $3 / 5$ & 60 & 60 & 5.25 \\
\hline 32 & 3200 & 3.5051 & $4 / 5$ & 80 & 80 & 5.84 \\
\hline 64 & 6400 & 3.8062 & $4 / 5$ & 80 & 80 & 5.84 \\
\hline 128 & 12800 & 4.1072 & $5 / 5$ & 100 & 95 & 6.64 \\
\hline
\end{tabular}

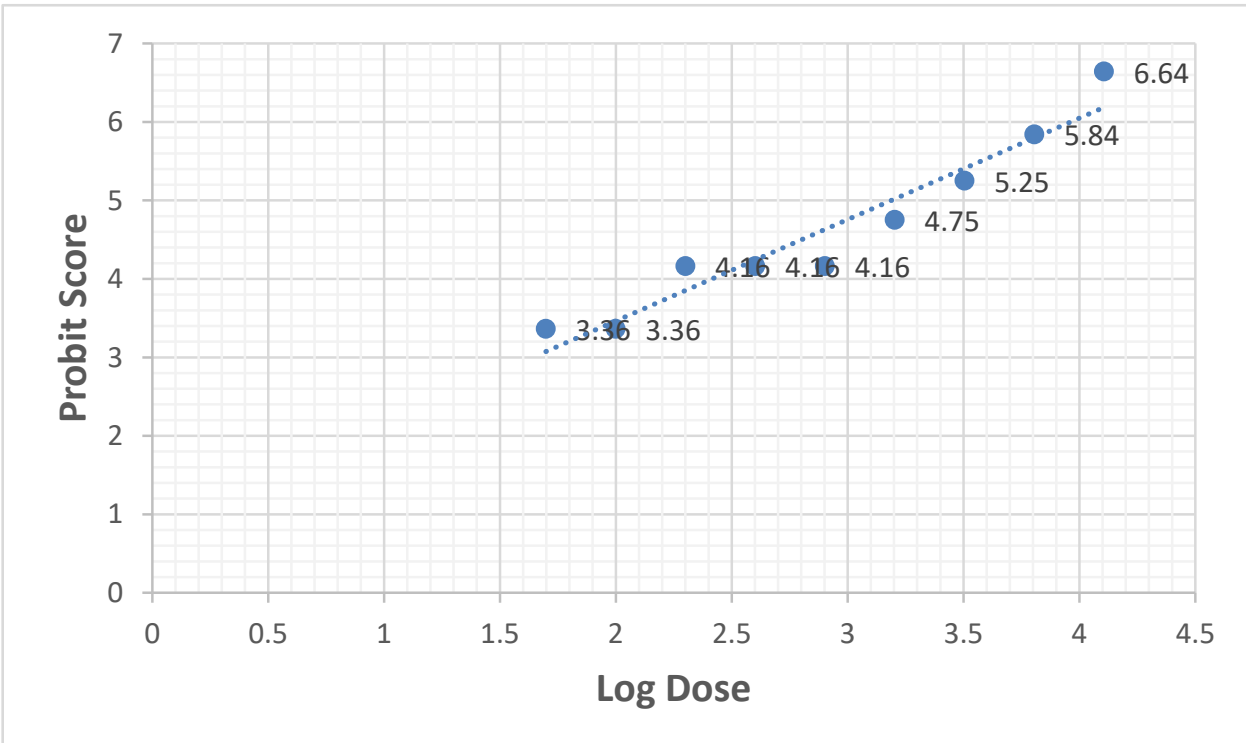

Figure-6: Graphical representation of effective dosage evaluation of MHNC against Naja naja venoms 


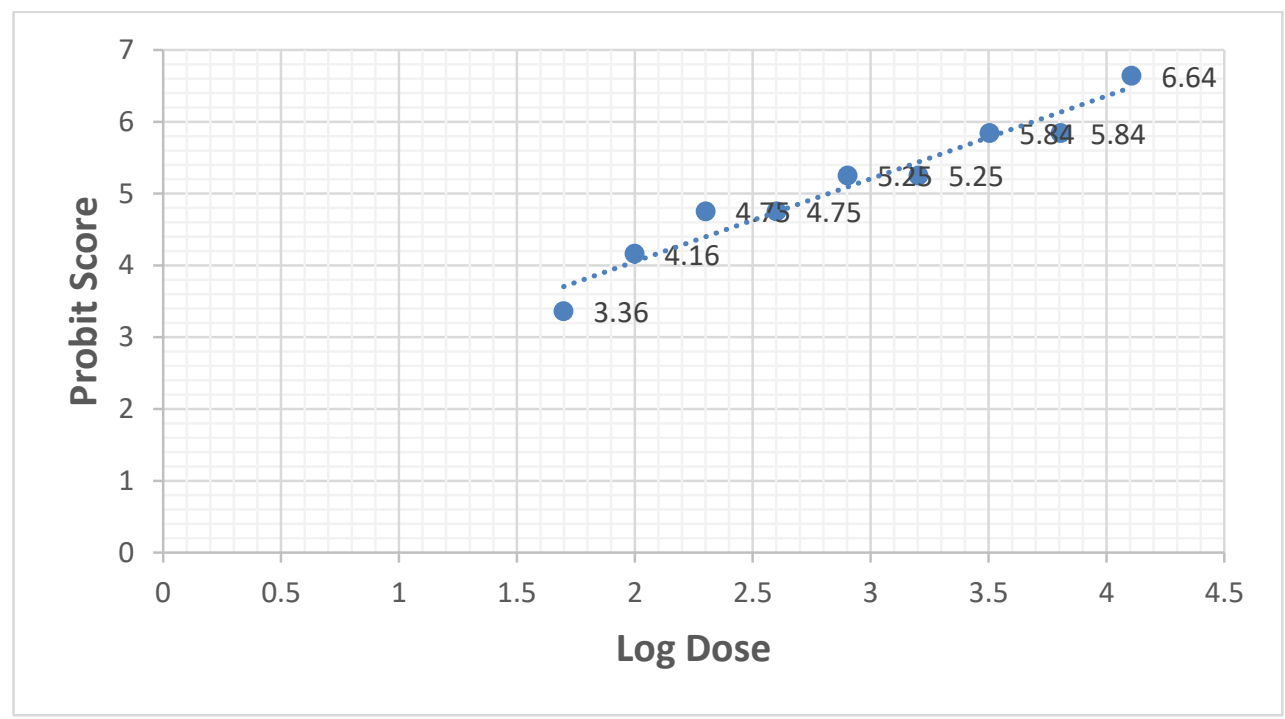

Figure-7: Graphical representation of effective dosage evaluation of MHNC against Bungarus Caeruleus venom

\section{Discussion}

The Indian cobra's venom mainly contains a powerful post-synaptic neurotoxin and cardiotoxin. The venom acts on the synaptic gaps of the nerves, thereby paralyzing muscles, and in severe bites leading to respiratory failure or cardiac arrest. The venom components include enzymes such as hyaluronidase that cause lysis and increase the spread of the venom. Envenomation symptoms may manifest between fifteen minutes and two hours following the bite. Though it is responsible for many bites, only a small percentage are fatal if proper medical treatment and anti-venom are given.(Asad et al., 2013) Mortality rate for untreated bite victims can vary from case to case, depending upon the quantity of venom delivered by the individual involved. According to one study, it is approximately 20 $30 \%$, but in another study involving victims who were given prompt medical treatment, the mortality rate was only $9 \%$. In Bangladesh it is responsible for most of the snake bite cases (Chethankumar and Srinivas, 2008).

The common krait's venom consists mostly of powerful neurotoxins, which induce muscle paralysis. Clinically, its venom contains presynaptic and postsynaptic neurotoxins, which generally affect the synaptic cleft (the points of information-transfer between neurons) (Theakston et al., 1990). In search for effective antivenom the present study developed a novel formulation of Metal-herbal Nano composite using copper nanoparticles and Leucas zeylanica extracts. 
Nanotechnology is a rapidly evolving subject that has the potential to revolutionize medicine. Metal nanoparticles are utilized as a substitute for drugs with a wide range of functions. Richard P. Feynman (1959) proposed the notion of nanoparticles, which are particles with a diameter of 1 to 100 nanometers with at least one dimension. In 1974, Norio Taniguchi created the phrase "Nanotechnology." As Nano medicine, it is utilized to treat patients. Metal nanoparticles have a wide range of applications, and their features are unique due to their physio-chemical features. Nanoparticles have recently been revealed to neutralize the toxicity and venom of many snakes, according to studies (Boisseau and Loubaton, 2011).

Nanotechnology applications in medicine have given rise to a new discipline known as "nanomedicine," which has the potential to develop revolutionary treatments for a wide range of ailments. The creation of nanomaterials is increasingly seen as a viable technique for controlling or treating pathogenic biofilms on indwelling medical devices and implants. Metals (e.g., copper, silver, iron, zinc, titanium, magnesium, or gold), metal oxides, polymers (e.g., nanoporous polymers), metal-based polymeric composites, peptides, or combinations of these, or liposomes, antibiotic encapsulated nanoparticles, or responsive smart nanomaterials that have antimicrobial effects but cause minimal damage to the host, are the majority of nanoparticles studied (Boisseau and Loubaton, 2011; McNamara and Tofail, 2017).

Plant-based medicines are still a valuable resource in the fight against serious diseases. Herbs are conjugated with metal (gold, silver, iron, etc.) ashes in Ayurveda to boost their potency. Nanoparticles and nano-based products are currently being used in biomedicine, and they have demonstrated to be a promising therapeutic molecule. Herbal-Metal nanocomposites have been discovered to be a unique formulation with a number of benefits over herbal extracts. Metals have been conjugated to botanicals since the dawn of time. It provides a number of benefits, including enhanced stability and activity. (Hasson et al., 2012). In the present study the developed MHNC had significant neutralization of snake venoms and led to survival of sensitized animals. Combination of plant extracts and copper nanoparticles showed synergistic mode of action in neutralizing venoms which was confirmed in our previous study. 


\section{Conclusion}

A novelistic approach on development of Metal herbal Nanocomposite was carried out in this study. The venoms were procured from Irula snake catchers society in lyophilised forms. Herbal - metal nanocomposites were prepared in 1:1 combinations. Single strength concentration of herbal and copper oxide metal nanoparticles was used to attain these ratio's. In vivo venom neutralization analysis was carried out in Swiss albino mice. The $\mathrm{LD}_{50}$ of the Naja naja venom was observed to be $0.19 \mu \mathrm{g} / \mathrm{g}$ and $0.174 \mu \mathrm{g} / \mathrm{g}$ for Bungarus Caeruleus venom. The $\mathrm{ED}_{50}$ of the MHNC against Naja naja venom was observed to be $14.22 \mathrm{mg}$ and $63.39 \mathrm{mg}$ for Bungarus Caeruleus venom. The MHNC developed in this study has significant venom neutralization potential against Naja naja and Bungarus Caeruleus venoms. Therefore, the MHNC can be used for development of anti-venom drugs. 


\section{References}

Amin, M.R., Mamun, S.M.H., Rashid, R., Rahman, M., Ghose, A., Sharmin, S., Rahman, M.R., Faiz, M.A., 2008. Anti-snake venom: Use and adverse reaction in a snake bite study clinic in Bangladesh. J. Venom. Anim. Toxins Incl. Trop. Dis. 14, 660-672. https://doi.org/10.1590/S1678-91992008000400009

Asad, M.H.H. Bin, Razi, M.T., Durr-e-Sabih, Najamus-Saqib, Q., Nasim, S.J., Murtaza, G., Hussain, I., 2013. Anti-venom potential of Pakistani medicinal plants: inhibition of anticoagulation activity of Naja naja karachiensis toxin. Curr. Sci.

Boisseau, P., Loubaton, B., 2011. Nanomedicine, nanotechnology in medicine. Comptes Rendus Phys. https://doi.org/10.1016/j.crhy.2011.06.001

Chen, G.Y., Zhang, B., Zhao, T., Nidhal, N., Jia-Li, W., Zhou, X.M., Chun-Yan, D., 2020. A new triterpenoid glucoside from Leucas zeylanica. Nat. Prod. Res. 34, 1874-1878. https://doi.org/10.1080/14786419.2019.1566820

Chethankumar, M., Srinivas, L., 2008. New biological activity against phospholipase A2 by Turmerin, a protein from Curcuma longa L. Biol. Chem. https://doi.org/10.1515/BC.2008.024

Ghulam, M., Hajira, T., Muhammad, S., Nasir, A., 2013. Synthesis and characterization of cupric oxide $(\mathrm{CuO})$ nanoparticles and their application for the removal of dyes.

African J. Biotechnol. https://doi.org/10.5897/ajb2013.13058

Goswami, P.K., Samant, M., Srivastava, R.S., 2014. Snake venom, anti-snake venom \& potential of snake venom. Int. J. Pharm. Pharm. Sci.

Hasson, S.S., Al-Balushi, M.S., Said, E.A., Habbal, O., Idris, M.A., Mothana, R.A.A., Sallam, T.A., Al-Jabri, A.A., 2012. Neutralisation of local haemorrhage induced by the saw-scaled viper Echis carinatus sochureki venom using ethanolic extract of Hibiscus aethiopicus L. Evidence-based Complement. Altern. Med. https://doi.org/10.1155/2012/540671

McNamara, K., Tofail, S.A.M., 2017. Nanoparticles in biomedical applications. Adv. Phys. X. https://doi.org/10.1080/23746149.2016.1254570

Sinha, K., 2011. Snake bites kill 46K in India yearly. The Times of India.

Sivaraman, T., Sreedevi, N.S., Meenatchisundaram, S., Vadivelan, R., 2017. Antitoxin activity of aqueous extract of Cyclea peltata root against Naja naja venom. Indian J. Pharmacol. https://doi.org/10.4103/ijp.IJP_708_16

Theakston, R.D.G., Phillips, R.E., Warrell, D.A., Galagedera, Y., Abeysekera, D.T.D.J., Dissanayaka, P., de Silva, A., Aloysius, D.J., 1990. Envenoming by the common krait (Bungarus caeruleus) and Sri lankan cobra (Naja naja naja): Efficacy and complications of therapy with haffkine antivenom. Trans. R. Soc. Trop. Med. Hyg. https://doi.org/10.1016/0035-9203(90)90297-R

Uhegbu, F., Elekwa, I., Ukoha, C., 2005. Comparative efficacy of crude aqueous extract of Mangiferea Indica, Carica Papaya and Sulphadoxine Pyrimethamine on mice infested with malaria parasite in vivo. Glob. J. Pure Appl. Sci. https://doi.org/10.4314/gjpas.v11i3.16523 